FAO. Faostat database gateway. 2000. http:// apps.fao.org/lim500/nph-wrap.pl? Production. Crops.Primary\&Domain=SU. Consultado em 25 de jul. de 2000.

FEDERER, W. T. Experimental design. New York: MacMillan, Company. 1955. 544 p. GROSSMANN, J.; FREITAS, A.C. Determinação do teor de matéria seca pelo peso específico em raízes de mandioca. Revista Agronômica, Porto Alegre, v. 160/162, n. 4, p. 75-80, 1950.

HATHEWAY, W.H.; WILLIAMS, E.J. Efficient estimation of the relationship between plot size and the variability of crop yields. Biometrics, v. 14, p. 207-222, 1958.

LESSMAN, K.J.; ATKINS, R.E. Optimum plot size and relative efficiency of lattice designs for grain sorghum yield tests. Crop Science, v. 3, n. 5 , p. 477-481, 1963.

LIN, C.S.; MORRISON, M.J.; BINNS, M.R. Persistence of a field heterogeneity index. Canadian Journal of Plant Science, v. 76, p. 245250, 1996.
LOZANO, J.C.; TORO, J.C.; CASTRO, A.; BELLOTI, A.C. Produção de material de plantio de mandioca. Cali, Colombia: CENTRO INTERNACIONAL DE AGRICULTURA TROPICAL. 28 p. 1977. (Série GP, 17).

MEIER, V.D.; LESSMAN, K.J. Estimation of optimum field plot shape and size for testing yield in Crambe abyssinica Hochst. Crop Science, v. 11, p. 648-650, 1971.

OLIVEIRA, P.H.; ESTEFANEL, V. Tamanho e forma da parcela para avaliação do rendimento em experimentos com batata. Ciência Rural, Santa Maria, v. 25, p. 205-220, 1995.

ORTIZ, R. Plot techniques for assessment of bunch weight in banana trials under two systems of crop management. Agronomy Journal, v. 87, p. 63-69, 1995.

ROCA, W.M.; NOLT, B.; MAFLA, G.; ROA, J., REYES, R. Eliminación de virus e propagación de clones en la yuca ( $M$. esculenta Crantz). In: ROCA, W.M.; MROGINSKI, L.A. (Eds.) Cultivo de tejidos en la agricultura, fundamentos $y$ aplicaciones. Cali, Colombia: CENTRO INTERNACIONAL DE AGRICULTURA TROPICAL. 1991. p. 403-420.
SINTHUPRAMA, S.; THIRAPORN, C.; SONHLAKSAP, N. Study on plot size and plot shape for cassava experiments. Progress report of 1973, Thailand Department of Agriculture. p. 262269.

STEEL, R.G.D.; TORRIE, J.H. Principles and procedures of statistics. 2a ed. New York: McGraw-Hill Book,. 1980. 633 p.

TINEO, J.R.; VILLASMIL, J.J. Determinacion del tamano optimo de parcela experimental en yuca (Manihot esculenta Crantz). Revista de la Facultad de Agronomia, Venezuela, v. 7, n. 2, p. 116-126, 1988

VALLEJO, R.L.; MENDOZA, H.A. Plot technique studies on sweet potato yield trials. Journal of the American Society for Horticultural Science, v. 117, n. 3, p. 508-511, 1992.

FREIRE JÚNIOR, M.; DELIZA, R.; CHITARRA, A.B. Alterações sensoriais em alface hidropônica cv. Regina minimamente processada e armazenada sob refrigeração. Horticultura Brasileira, Brasília, v. 20, n. 1, p. 63-66, março 2.002.

\title{
Alterações sensoriais em alface hidropônica cv. Regina minimamente processada e armazenada sob refrigeração.
}

\author{
Murillo Freire Júnior ${ }^{1}$; Rosires Deliza ${ }^{1}$; Adimilson Bosco Chitarra ${ }^{2}$ \\ ${ }^{1}$ Embrapa Agroindústria de Alimentos, Av. das Américas, 29501, Guaratiba, 23.020-470 Rio de Janeiro-RJ. E-mail: \\ mfreire@ctaa.embrapa.br; ${ }^{2}$ UFLA, Caixa Postal 37, CEP 37.200-000 Lavras-MG
}

\section{RESUMO}

Com o aumento da demanda por frutas e hortaliças minimamente processadas, a manutenção da qualidade destes produtos é um fator fundamental. $\mathrm{O}$ consumidor exige um produto fresco, de aspecto saudável, com boas características de cor, bem como outros atributos desejáveis na sua aparência. Foram avaliadas algumas alterações sensoriais em alface hidropônica, cv. Regina, minimamente processada, acondicionada em sacos plásticos termosoldados e armazenadas a $2^{\circ} \mathrm{C}$ e $10^{\circ} \mathrm{C}$. Independente da temperatura de armazenamento, até o terceiro dia, nenhum comprometimento do produto houve para qualquer dos aspectos de qualidade analisados: cor, frescor, escurecimento da nervura central, escurecimento de bordas, aspecto de podre e sabor de cozido. No armazenamento a $2^{\circ} \mathrm{C}$ a alface apresentou uma vida de prateleira de sete dias, sem comprometimento das suas principais características de aparência, ou seja, não houve escurecimento e a cor e o frescor se mantiveram inalterados. Para o produto armazenado a $10^{\circ} \mathrm{C}$, as alterações ocorridas tornaram o produto indesejável após o terceiro dia.

\section{ABSTRACT}

Sensorial changes of minimally processed hydroponic lettuce cv. Regina stored under refrigeration.

The maintenance of the sensorial quality of minimally processed fruits and vegetables is becoming a fundamental factor due to the increasing demand for these products. The consumer looks for a fresh product with healthy appearance and good color characteristics, as well as other desirable attributes in its appearance. Some sensorial characteristics were evaluated in minimally processed hydroponic lettuce, cv. Regina conditioned in thermally sealed plastic bags and stored at $2^{\circ} \mathrm{C}$ and $10^{\circ} \mathrm{C}$. For both storage temperatures, there was no significant product modification regarding the analyzed quality aspects like color, freshness, browning, rotten aspect and cooked flavor up to the third day of the experiment. At $2^{\circ} \mathrm{C}$ the lettuce presented a shelf life of 7 days without compromising its main sensorial characteristics as color, freshness and browning. For the product stored at $10^{\circ} \mathrm{C}$ the shelf life was up to 3 days.

Keywords: Lactuca sativa, fresh-cut, shelf life.

Palavras-chave: Lactuca sativa, pré-cortados, conservação.

\section{(Aceito para publicação em 03 de dezembro de 2.001)}

$\mathrm{O}$ consumidor vem apresentando cada vez maior consciência na escolha de sua alimentação, porém com menor tempo disponível para preparar refeições saudáveis. Como resultado, o mercado e a demanda por frutas e vegetais minimamente processados têm aumentado rapidamente, proporcionando o surgimento de produtos convenientes, ou seja, produtos frescos que podem ser preparados e consumidos em pouco tempo (Burns, 1995). Seguindo uma tendência mundial, muitos consumidores brasileiros resolveram utilizar pratos semi-prontos e vegetais pré-cortados. Os 
Tabela 1. Média das notas atribuídas para a alface hidropônica cv. Regina minimamente processada, embalada em saco plástico termosoldado, durante armazenamento a $2^{\circ} \mathrm{C}$ e $10^{\circ} \mathrm{C}$. Rio de Janeiro, Embrapa Agroindústria de Alimentos, 2000.

\begin{tabular}{|c|c|c|c|c|c|c|c|c|c|}
\hline \multirow{3}{*}{ Atributo } & \multicolumn{9}{|c|}{ Tempo de armazenamento (dias) } \\
\hline & \multirow{2}{*}{0} & \multicolumn{2}{|r|}{3} & \multicolumn{2}{|c|}{7} & \multicolumn{2}{|c|}{10} & \multicolumn{2}{|c|}{14} \\
\hline & & $2^{\circ} \mathrm{C}$ & $10^{\circ} \mathrm{C}$ & $2^{\circ} \mathrm{C}$ & $10^{\circ} \mathrm{C}$ & $2^{\circ} \mathrm{C}$ & $10^{\circ} \mathrm{C}$ & $2^{\circ} \mathrm{C}$ & $10^{\circ} \mathrm{C}$ \\
\hline Cor & $8,93 \pm 0,16$ & $8,95 \pm 0,14$ & $8,61 \pm 0,91$ & $8,44 \pm 0,79$ & $7,75 \pm 0,87$ & $8,57 \pm 0,84$ & $6,53 \pm 1,97$ & $8,22 \pm 0,68$ & $1,01 \pm 0,03$ \\
\hline Frescor & $8,73 \pm 0,37$ & $8,65 \pm 0,43$ & $8,04 \pm 0,79$ & $7,68 \pm 1,06$ & $5,85 \pm 1,49$ & $7,47 \pm 1,60$ & $2,33 \pm 1,59$ & $5,20 \pm 2,22$ & $1,00 \pm 0,00$ \\
\hline ENC & $0,00 \pm 0,00$ & $0,14 \pm 0,16$ & $0,79 \pm 0,94$ & $0,94 \pm 1,15$ & $1,32 \pm 1,33$ & $1,15 \pm 0,91$ & $5,12 \pm 1,99$ & $3,04 \pm 1,92$ & $8,73 \pm 0,63$ \\
\hline EB & $0,02 \pm 0,00$ & $0,07 \pm 0,10$ & $0,91 \pm 1,01$ & $0,38 \pm 0,38$ & $2,49 \pm 1,78$ & $0,78 \pm 0,76$ & $5,11 \pm 2,65$ & $2,40 \pm 1,40$ & $7,92 \pm 2,20$ \\
\hline $\mathrm{COZ}$ & $0,74 \pm 0,84$ & $0,58 \pm 0,77$ & $1,07 \pm 0,79$ & $1,26 \pm 1,37$ & $1,81 \pm 1,45$ & $1,16 \pm 1,01$ & $4,39 \pm 2,26$ & $3,03 \pm 2,34$ & $8,10 \pm 2,41$ \\
\hline PO & $0,00 \pm 0,00$ & $0,01 \pm 0,03$ & $0,08 \pm 0,20$ & $0,01 \pm 0,04$ & $2,11 \pm 1,47$ & $0,00 \pm 0,00$ & $5,85 \pm 2,20$ & $0,23 \pm 0,35$ & $9,00 \pm 0,00$ \\
\hline IGA & $8,49 \pm 0,46$ & $8,55 \pm 0,39$ & $7,52 \pm 0,71$ & $7,46 \pm 1,09$ & $4,81 \pm 1,56$ & $7,42 \pm 1,21$ & $2,50 \pm 1,38$ & $5,03 \pm 1,70$ & $1,00 \pm 0,00$ \\
\hline
\end{tabular}

ENC: Escurecimento da nervura central; EB: Escurecimento das bordas; COZ: Aspecto cozido; PO: Aspecto podre; IGA: Impressão global da aparência

supermercados estão ampliando cada vez mais as seções deste tipo de produto. Segundo dados da consultoria Nielsen, no Brasil este nicho de mercado começou a ser explorado em 1994 e, em apenas um ano cresceu 68,9\% em volume consumido no varejo e. em 1996 movimentou cerca de $\mathrm{R} \$ 400$ milhões em vendas (Jornal do Brasil, 21/6/1997).

A alface é considerada uma hortaliça folhosa importante na alimentação do brasileiro, o que assegura à cultura expressiva importância econômica. É uma das culturas mais produzidas em hidroponia, o que permite seu cultivo durante o ano todo, com grande produtividade, com qualidade e sem o risco de contaminação por microrganismos veiculados pelo solo.

Este trabalho teve por objetivo avaliar as alterações das principais características sensoriais da alface hidropônica minimamente processada, cv. Regina, para obter informações que permitam preservar sua qualidade, por uma maior período de armazenamento.

\section{MATERIAL E MÉTODOS}

As 90 plantas inteiras de alface (cv. Regina) cultivadas em sistema de hidroponia, foram procedentes da região serrana de Miguel Pereira, Rio de Janeiro. As amostras foram colhidas, ao acaso, pela manhã, e selecionadas por sua uniformidade, com peso médio unitário de 450 gramas, sendo pré-resfriadas em água gelada $\left(5^{\circ} \mathrm{C}\right)$ e levadas para a planta-piloto para seu processamento. Em seguida, foram cortadas as raízes e retiradas as folhas externas.
As folhas restantes, lavadas individualmente em água potável, foram cortadas com facas de aço inoxidável, com um único movimento e sentido transversal ao longo da nervura central, de maneira a se obter tiras com $20 \pm 2 \mathrm{~mm}$ de largura, seguindo a metodologia proposta por Hurst (1995). As folhas cortadas foram novamente lavadas, por imersão em água fria $\left(5-8^{\circ} \mathrm{C}\right)$ com $100 \mathrm{ppm}$ de cloro livre, ajustado em $\mathrm{pH}$ 7,0 por 15 minutos, e centrifugadas por 1 minuto em centrifuga marca Fanem modelo 204-NR, a $1500 \mathrm{rpm}$.

$\mathrm{O}$ produto foi acondicionado manualmente, em sacos plásticos de BOPP/ PEBD (Polipropileno bi-orientado/ Polietileno de baixa densidade) em porções de $100 \mathrm{~g}$ e, armazenado em câmaras $\mathrm{BOD}$, às temperaturas de $2^{\circ} \mathrm{C} \pm 1^{\circ} \mathrm{C} \mathrm{e}$ $10 \pm 1^{\circ} \mathrm{C}$, que representam, respectivamente, as condições ótimas recomendadas e as encontradas nos pontos de venda a varejo.

A avaliação da aparência da alface foi realizada aos $0 ; 3 ; 7 ; 10$ e 14 dias, utilizando equipe de sete provadores selecionados pela aptidão superior em discriminar cor. Amostras do produto em diferentes estádios de conservação, variando de fresco a bastante senescente, foram apresentadas à equipe durante a fase de treinamento, a fim de estimular e enriquecer a discussão, possibilitando o levantamento e a definição dos atributos sensoriais: cor (verde-claro característico da alface, tom homogêneo, uniforme, sem manchas ou áreas descoloradas ou amarelecidas); frescor (aspecto viçoso, vivo e brilhante); escurecimento da nervura central (áreas avermelhadas, escuras e/ou marrons, localizadas nas margens laterais da nervura central); escurecimento das bordas (áreas avermelhadas, escuras e/ou marrons, localizadas nas margens laterais do tecido cortado e do limbo foliar); cozido (aspecto ressecado, quebradiço, murcho, amolecido, sem rigidez; sem turgor celular); podre (aspecto deteriorado, enegrecido, melado, com exsudação e odor desagradável acentuados); impressão global da aparência (aspecto global, incluindo todos os atributos juntos, conferindo qualidade ao produto). Os atributos de cor, frescor, escurecimento da nervura central, escurecimento das bordas, cozido e podre foram avaliados em escalas não estruturadas de nove pontos ancoradas nos extremos correspondendo a 1 e 9 (onde: 1 = não característica, pouco, nenhum, nenhum, ausente, ausente; $9=$ característica, e muito para os demais atributos). A impressão global de aparência seguiu escala que variou de $1=$ muito ruim a $9=$ muito boa.

Cada amostra foi composta por três sacos contendo 100 gramas de alface cortada, codificada com número de três dígitos e apresentada aos provadores em bandejas de aço inoxidável forradas com papel branco. Os testes foram realizados em cabines individuais de prova sob iluminação branca, imitando a luz do dia. A ordem de apresentação das amostras seguiu delineamento de blocos completos balanceados (MacFie et al., 1989) e os produtos foram avaliados em duplicata. As notas conferidas pelos provadores foram tabuladas, e as médias submetidas à análise de variância e 
comparadas pelo teste de Tukey a nível de $5 \%$, através do programa estatístico Sanest (Machado \& Zonta, 1991). Através do programa estatístico SANEST, foi determinada a correlação linear (correlações de Pearson) entre os atributos sensoriais, para cada temperatura de armazenamento.

\section{RESULTADOS E DISCUSSÃO}

Os resultados mostraram que a temperatura, o tempo de armazenamento e a interação tempo-temperatura afetaram significativamente todos os atributos sensoriais estudados relacionados com a aparência da alface cortada.

As médias das notas atribuídas pelos provadores estão apresentadas na Tabela 1.

Observou-se que até o terceiro dia não houve alteração perceptível da cor da alface minimamente processada, em nenhuma das temperaturas de armazenamento. Após o sétimo dia, as diferenças na cor em ambas as temperaturas foram perceptíveis, sendo muito menos acentuadas a $2^{\circ} \mathrm{C}$. À temperatura de $10^{\circ} \mathrm{C}$, após o sétimo dia, houve perda na cor característica da alface, evidenciando comprometimento da qualidade. A alteração da cor pode ser atribuída à degradação da clorofila e à formação de compostos secundários, o que reduz sensivelmente a qualidade do produto.

Os padrões respiratórios para hortaliças em resposta às temperaturas mais baixas são variáveis. No caso específico da alface, como existe tolerância a temperaturas próximas a $2^{\circ} \mathrm{C}$, verificou-se que o frescor nesta temperatura foi mantido praticamente inalterado até o sétimo dia. A temperatura mais baixa propiciou um taxa respiratória adequada para assegurar o equilíbrio com a glicólise, mantendo um metabolismo normal, conforme constatado por Lyons (1973) em hortaliças tolerantes ao chilling. Este fato não ocorreu à temperatura de $10^{\circ} \mathrm{C}$, pois no sétimo dia de armazenamento a média seis atribuída pelos provadores foi interpretada como perda de frescor e consequentemente de valor comercial.

Apesar dos ferimentos ou cortes induzirem o escurecimento e serem fatores limitantes para a conservação de hortaliças minimamente processadas, a temperatura de $2^{\circ} \mathrm{C}$ foi eficiente para evitar, até o décimo dia, o escurecimento da nervura central, o que não ocorreu à temperatura de $10^{\circ} \mathrm{C}$.

Não se observaram diferenças no escurecimento das bordas do produto, até o terceiro dia, para as duas temperaturas de armazenamento. No produto armazenado a $2^{\circ} \mathrm{C}$, observou-se escurecimento mais lento e gradual, sendo que até o décimo dia, o produto manteve-se com boa qualidade. No produto armazenado a $10^{\circ} \mathrm{C}$ ocorreu aumento constante e mais acentuado no escurecimento, sendo que após o terceiro dia, esta alteração ficou bem evidenciada, comprometendo a qualidade do produto.

Segundo López-Gálvez et al. (1996), dentre os diferentes componentes que interferem na aparência da alface précortada, o escurecimento da superfície da folha e o das bordas são os maiores defeitos que levam à diminuição da qualidade das saladas produzidas com esta hortaliça pré-cortada, na ausência da desordem denominada russet spotting. No armazenamento a $10^{\circ} \mathrm{C}$, após o sétimo dia, a diferença no escurecimento foi significativa, quando comparado ao produto armazenado a $2^{\circ} \mathrm{C}$.

Observou-se que até o sétimo dia, não houve diferença significativa no atributo cozido, entre as duas temperaturas de armazenamento. No produto armazenado a $2^{\circ} \mathrm{C}$, não ocorreu diferença significativa até o décimo dia enquanto que a $10^{\circ} \mathrm{C}$, esta diferença foi mais acentuada após sete dias.

Observou-se também que o material de embalagem utilizado evitou a perda de umidade, via evaporação, retardando o murchamento ou perda do turgor do produto, ajudando a manter a sua qualidade. É possível que o principal fator de alteração do atributo cozido tenha sido a elevação do teor de $\mathrm{CO}_{2}$ à temperatura de $10^{\circ} \mathrm{C}$, conforme constatado por López-Galvez et al. (1996) e por Siriphanic \& Kader (1985).

No produto conservado a $2^{\circ} \mathrm{C}$ não ocorreu diferença significativa no atributo podre até o décimo quarto dia, enquanto durante o armazenamento a $10^{\circ} \mathrm{C}$, houve diferença acentuada após o terceiro dia.

Até o terceiro dia, não houve diferença significativa no atributo Impres- são global da aparência, para as duas temperaturas de armazenamento. A partir do terceiro dia observou-se diferença na impressão global da aparência do produto armazenado nas duas temperaturas. Durante o armazenamento a $2^{\circ} \mathrm{C}$, o produto permaneceu em boas condições até por 10 dias, com uma queda gradual e mais lenta na qualidade. Para o produto armazenado a $10^{\circ} \mathrm{C}$, após o sétimo dia notou-se grande e acentuada diminuição na qualidade.

Tais resultados estão em concordância com Bolin et al. (1977), que reportam que o armazenamento à baixa temperatura é método importante de preservação para produtos minimamente processadas como a alface cortada da cultivar Iceberg. McDonald et al. (1990), estudaram a alface crespa cortada cv. Salinas, utilizando diferentes filmes plásticos, armazenadas a $1^{\circ} \mathrm{C}$ e $5^{\circ} \mathrm{C}$ por 14 dias, e comentaram que a aparência e o sabor foram mais afetados pela temperatura do que pelo tempo do armazenamento, em três dos quatro tipos de filme utilizados.

Com relação à correlação linear, observou-se que para ambas temperaturas de armazenamento, houve correlação significativa entre os atributos $\left(r_{1}\right.$ $\left.=2^{\circ} \mathrm{C} ; \mathrm{r}_{2}=10^{\circ} \mathrm{C}\right)$. A cor apresentou alta associação positiva com frescor $\left(\mathrm{r}_{1}=\right.$ 0,$9304 ; r_{2}=0,8653$ ) e a impressão global da aparência $\left(r_{1}=0,9326 ; r_{2}\right.$ $=0,8582$ ), e uma alta associação negativa com escurecimento da nervura central $\left(r_{1}=-0,9283 ; r_{2}=-0,9574\right)$, escurecimento das bordas $\left(r_{1}=-0,8542\right.$; $\left.r_{2}=-0,9397\right)$ e com os atributos cozido $\left(r_{1}=-0,8976 ; r_{2}=-0,9796\right)$ e podre $\left(r_{1}=-\right.$ $\left.0,7362, r_{2}=-0,9348\right)$. Da mesma maneira, o frescor do produto apresentou alta associação positiva com a cor $\left(\mathrm{r}_{1}=\right.$ 0,$9304 ; r_{2}=0,8653$ ) e a impressão global da aparência $\left(r_{1}=0,9982 ; r_{2}\right.$ $=0,9920$ ), e alta associação negativa com escurecimento da nervura central $\left(r_{1}=-0,9999 ; \quad r_{2}=-0,9572\right)$, escurecimento das bordas $\left(\mathrm{r}_{1}=-0,9849\right.$; $\left.\mathrm{r}_{2}=-0,9835\right)$ e com os atributos cozido $\left(\mathrm{r}_{1}=-0,9825 ; \mathrm{r}_{2}=-0,9388\right)$ e podre $\left(\mathrm{r}_{1}=\right.$ $\left.0,9065, r_{2}=-0,9834\right)$. O escurecimento da nervura central apresentou alta correlação positiva com o escurecimento das bordas $\left(r_{1}=0,9853 ; r_{2}=0,9869\right)$, com os atributos aspectos cozido $\left(r_{1}=0,9799\right.$; 
$\left.\mathrm{r}_{2}=0,9953\right)$ e podre $\left(\mathrm{r}_{1}=0,9045 ; \mathrm{r}_{2}\right.$ $=0,9889$ ) e apresentaram altas correlações negativas em relação à cor $\left(\mathrm{r}_{1}=\right.$ 0,$\left.9283 ; r_{2}=-0,9574\right)$, ao frescor $\left(r_{1}=-\right.$ 0,$\left.9999 ; r_{2}=-0,9572\right)$ e impressão global da aparência $\left(r_{1}=-0,9971 ; r_{2}=-0,9347\right)$.

As médias das notas mostraram que no armazenamento a $2^{\circ} \mathrm{C}$ os primeiros sinais de deterioração na qualidade iniciam-se pelo atributo cozido, seguido pelo escurecimento da nervura central, escurecimento de bordas e do aspecto podre, enquanto que a $10^{\circ} \mathrm{C}$ o atributo cozido foi o sinal mais evidente somente até o terceiro dia. Após este período, o escurecimento da nervura central, o escurecimento de bordas e o aspecto podre aparecem praticamente juntos.

O escurecimento da nervura central foi mais intenso que o escurecimento das bordas, alcançando médias superiores nos mesmos períodos, em ambas as temperaturas. Estas médias também mostraram que a $10^{\circ} \mathrm{C}$, após o sétimo dia, quando a concentração de $\mathrm{CO}_{2}$ atingiu valores próximos de $6 \%$, o escurecimento da nervura central e o escurecimento das bordas cresceu acentuadamente. Contudo, a $2^{\circ} \mathrm{C}$ somente após o décimo dia observou-se aumento no escurecimento da nervura central e do escurecimento de bordas, sendo bem menor que o do produto armazenado a $10^{\circ} \mathrm{C}$.

Através dos resultados obtidos nas condições experimentais do presente trabalho, conclui-se que para ambas temperaturas de armazenamento $\left(2^{\circ} \mathrm{C}\right.$ e $10^{\circ} \mathrm{C}$ ), não houve nenhum comprometimento do produto com qualquer um dos aspectos de qualidade sensorial analisados, até o terceiro dia: a alface hidropônica, cv. Regina, minimamente processada, armazenada a $2^{\circ} \mathrm{C}$, apresentou tempo de prateleira de 7 dias, sem comprometer suas principais características sensoriais; já para o produto armazenado a $10^{\circ} \mathrm{C}$, a vida de prateleira foi no máximo, de 3 dias, devido principalmente à alteração na cor e ao escurecimento acentuado da nervura central e escurecimento das bordas.

\section{AGRADECIMENTOS}

À CAPES, pelo auxílio financeiro.

\section{LITERATURA CITADA}

BURNS, J.K. Lightly processed fruits and vegetables: introduction to the colloquium. HortScience, v. 30, n. 1, p. 14, 1995.
BOLIN, H.R.; STAFFORD, A.E.; KING JR., A.D.; HUXSOLL, C.C. Factors affecting the storage stability of shredded lettuce. Journal of Food Science, v. 42, p. 1319-1321, 1977.

HURST, W.C. Sanitation of lightly processed fruits and vegetables. HortScience, v. 30, n. 1, p. 22-24, 1995.

Jornal do Brasil, Rio de Janeiro, 21 de junho de 1997- $1^{\circ}$ Caderno, p. 17.

LÓPEZ-GÁLVEZ, G.; SALTVEIT, M.; CANTWELL, M. The visual quality of minimally processed lettuces storaged in air or controlled atmosphere with emphasis on romaine air iceberg types. Postharvest Biology and Tecnology, v. 8, p. 179-190, 1996.

LYONS, J.M. Chilling injury in plant. Annual Review Plant Physiology, v. 24, p. 445-466, 1973. MacFIE, H.J.H.; BRATCHELL, N.; GRENHOFF, K.; VALLIS, L.V. Designs to balance the effect of order of presentation and first-order carry-over effects in hall tests. Journal Sensory Studies, v. 4, p. 129-148, 1989.

MACHADO, A.A.; ZONTA, E.P. Manual do Sanest: Sistema de análise estatística para microcomputadores. Pelotas: UFPel, 1991. 102 p. McDONALD, R.E.; RISSE, L.A.; BARMORE, C.R. Bagging chopped lettuce in selected permeability films. HortScience, v. 25, n. 6, p. 671673, 1990.

SIRIPHANIC, J. ; KADER, A.A. Effects of $\mathrm{CO}_{2}$ on total phenolics, phenyl alamine ammonia lyase and polyphenoloxidase in lettuce tissue. Journal of American Society and Horticultural Science, v. 110, p. 249-253, 1985. 